\title{
La «cuestión urbana»: apuntes para un diagrama de la relación gobierno y policía en Michel Foucault
}

\author{
The 'urban question': notes to a diagram of the relation \\ government and police on Michel Foucault \\ PATRICIO LANDAETA MARDONES, JUAN IGNACIO ARIAS KRAUSE Y RICARDO \\ ESPINOZA LOLAS \\ Centro de Estudios Avanzados, Universidad de Playa Ancha (Chile) / Pontificia Universidad Católica \\ de Valparaíso (Chile)
}

Artículo recibido: 12 octubre 2016 Solicitud de revisión: 7 enero 2017 Artículo aceptado: 26 mayo 2017

Resumen

El artículo aborda la "cuestión urbana» en la modernidad desde el marco de los estudios de la gubernamentalidad desarrollado por Michel Foucault, tomando la siguiente hipótesis: la policía no solo es fundamento de la ciudad moderna, sino también de la proliferación de saberes y técnicas que proyectan y construyen a la par un orden social y espacial, que persigue paralelamente la «felicidad» de los ciudadanos y el «incremento del poder» del Estado. El fin es mostrar que el estrecho vínculo de «policía» $\mathrm{y}$ «saber social» en el gobierno de la población constituye el acelerador de la erosión del sentido político de la ciudad, definido por el conflicto ciudadano.

Palabras clave: gobierno, ciudad, policía, urbano, Foucault

\begin{abstract}
This article examines the «urban question» in modernity, reading Foucault's studies on governmentality. The hypothesis considers that Police is not only the foundation of the modern city, but also of the proliferation of knowledges and techniques that project and construct a social and spatial order, which pursues in parallel the «happiness» of citizens and the «increase of power» of the State. The aim is to show that the close link of "police» and «social knowledge» in the government of the population constitutes the accelerator of the erosion of the political sense of the city, defined by the citizen conflict.
\end{abstract}

Keywords: Government, City, Police, Urban, Foucault 


\section{INTRODUCCIÓN}

Que la filosofía debiese ser comprendida como una "geofilosofía», al estar menos ligada a la relación de sujeto y objeto que a la relación de tierra y territorio (Deleuze y Guattari, 1993: 86), nos parece una afirmación oportuna para introducir un estudio de la cuestión urbana en Foucault. En los escritos de Foucault se hace notar un marcado interés por examinar el lugar que ocupa - o es forzado a ocupar- el sujeto, individual y colectivamente, en distintas épocas, tanto que podríamos interpretar su trabajo de acuerdo al deseo de cartografiar la relación de espacio y poder. A partir de este presupuesto podríamos sondear su inclinación por el estudio de disciplinas como arquitectura, geografía, historia.

En el apartado «Geofilosofía» de ¿Qué es la filosofía?, se sostiene que el surgimiento de la filosofía se debería menos a una necesidad que a una contingencia cifrada en la inmanencia que ofrece la polis: en el borde del imperio persa la ciudad griega ofrece a ricos y pobres un medio, una atmósfera para la asociación y rivalidad en el plano político, como para la libre expresión de perspectivas y puntos de vistas en el plano del pensamiento filosófico, imposibles bajo el despotismo oriental. Y si la filosofía sobrevive al horizonte griego, no es en razón de un destino, es gracias a la inmanencia de las ciudades mediterráneas que constituyen un medio desterritorializado para el capitalismo que se reterritorializa en el estado (Deleuze y Guattari, 1993: 97-98).

El medio actual de la filosofía, tan lejos y tan cerca de la inmanencia de Grecia y el Mediterráneo, es el capitalismo y el estado moderno, la abstracción que estos operan. Más concretamente, el levantamiento de territorios y sus implicaciones para las colectividades y grupos humanos. Pero capitalismo y estado constituyen, desde la óptica de una geofilosofía, solo el presente de la filosofía, el presente frente al cual cabe apelar a un pueblo nuevo (Deleuze y Guattari, 1993: 108). Por ello, más que procurar la representación de este presente, la creación de conceptos en filosofía implica trazar un mapa o "diagrama» que, sin pretensión de necesidad, traza los contornos de aquello que deviene y se hurta a la historia (Deleuze y Guattari, 1993: 97). La idea de Deleuze - retratar a Foucault, desmarcándolo de la historia, como un cartógrafo- es muy gráfica a este respecto, porque así en el autor de La bistoria de la locura no se percibe tanto una obsesión por la historia como por las discontinuidades que genera el levantamiento de un orden aparentemente infranqueable. Para una crítica política 
efectiva, lo que interesa es advertir las transformaciones y movimientos que remecen todo orden supuesto (Foucault, 1994a: 160).

La «cuestión urbana», objeto de este estudio, se ofrece como un campo de análisis privilegiado, ya que rastreando los elementos que inciden en la constitución de lo urbano se hace posible apreciar el devenir -los deslizamientos- de la noción de gobierno. Notemos primero que el término gobierno posee una geografía escarpada: desde su surgimiento conoce variadas transformaciones en el plano teórico y práctico, en razón de la distintas perspectivas que confluyen en su análisis - filosofía política, derecho, ciencias sociales, etc. - y, con ello, de los distintos modelos en los que opera -familiar-económico, policial-administrativo, social, etc. Notemos luego que por cuestión urbana aludimos al problema de la organización y jerarquización del territorio para la gestión de la vida tras la crisis de la relación ciudad y política, manifiesta en el vínculo cada vez más estrecho de gobierno y policía. ${ }^{1}$ La cuestión urbana comprende aquí el estudio de la ciudad, el surgimiento de lo urbano y su relación con el territorio y la circulación en una selección de textos y seminarios de Foucault, intentando entrar en diálogo con otros autores con el fin de ofrecer un diagrama tentativo del problema, evitando reproducir a Foucault (Acanda, 2001: 71). El vínculo del problema del gobierno con las transformaciones de la ciudad en Europa ha sido abordado con profundidad en La città biopolitica (2005) (Cavaletti, 2010). Allí se deja ver que la pluralidad de fines que se arrogan gobierno y policía solo pueden ser unificados y totalizados por un espacio como el territorio de la ciudad. No obstante, la ciudad moderna, desde sus primeros pasos hasta su fin en la metrópolis, no es ni un mero modelo, ni un contenedor de discursos y prácticas. Al contrario, como la política, es ella misma efecto de la relación de espacio y poder. Analizando la cuestión urbana, intentamos precisamente indagar en dicha relación.

El artículo se dividirá en tres partes: en la primera, se examinará el surgimiento de la idea de gobierno - su carácter físico y existencial- mostrando

1 Hay que diferenciar nuestra postura del texto homónimo de Castells (1977). Allí se pretendía mostrar que las demandas y acciones colectivas en el acontecer cotidiano divergen de las políticas públicas impulsadas por los gobiernos, caen fuera de la agenda de las organizaciones sindicales y no se identifican más con la organización tradicional en partidos. En ese marco, diagnostica el surgimiento de un nuevo sujeto político: los movimientos sociales urbanos. Esta idea sintoniza con la crítica de la "civilización urbana», analizada desde los años sesenta en Francia por filósofos, sociólogos geógrafos y urbanistas, sensibles a las repercusiones de las movilizaciones del llamado "mayo del 68». La postura común de esta crítica consiste en proponer ideas y acciones concretas para un nuevo «derecho de ciudad", que tendría por fin transformar consumidores en ciudadanos, revitalizando la dimensión política del espacio habitado, debe enfrentar, por un lado, la apropiación meramente instrumental de la dimensión urbana, por otro, debe hacer frente a la perpetua desterritorialización que produce el capitalismo. 
en qué circunstancias se produce su relación con la policía. En la segunda, se profundizará en la concepción de la policía con el fin de mostrar el modo en que conquista su lugar de privilegio y cómo se relaciona con el surgimiento de un saber social, correlato de la caída del universo político, y de la integración de la policía en dicho saber. Finalmente, el análisis se concentrará en el estudio de la metrópolis para intentar comprender cómo opera la cuestión urbana y en qué modo desafía el pensamiento filosófico.

\section{DEL ARTE DE GOBERNAR A LA POLICÍA}

La noción de gobierno irrumpe en el siglo XVI adquiriendo un rápido protagonismo en el horizonte político, hecho que se confirma al advertir el amplio espectro de situaciones que comprende. Expresiones tales como "gobierno de sí1", "gobierno de las almas y conductas», "gobierno de los niños» y «gobierno del estado» son cada vez más frecuentes, formando una constelación que remece el firmamento político hasta entonces conocido y defendido al volcar la mirada hacia lo existencial, afectando a toda materia tocante al poder desde un punto de vista natural, físico o positivo. En el seminario Seguridad Territorio y Población (1978-1979), Foucault reparó expresamente en este asunto: «me parece que hay algo absolutamente esencial en una física del poder o un poder que se piense como acción física en el elemento de la naturaleza y un poder que se piense como regulación solo capaz de producirse a través de la libertad de cada uno y con apoyo en ella» (Foucault, 2006: 71).

El problema del gobierno puede ser considerado como la cara visible de un inusitado fenómeno que pone en crisis tanto la teoría como la praxis política que inicia Aristóteles, ya que la noción de gobierno prontamente se identifica con el ejercicio de un poder propiamente humano, que se ejerce sobre un territorio constituido por cosas y hombres, mostrándose como epifenómeno de la caída del horizonte metafísico y teológico encargado de los asuntos del hombre hasta el nacimiento del estado moderno.

El término gobierno se hace célebre en $E l$ príncipe, de Maquiavelo, donde se ofrece toda una tipología no esencialista volcada sobre la contingencia que amenaza a un gobernante como el príncipe, todavía visto como «singularidad trascendente» (Foucault, 2006: 117); toda una travesía que recorre las formas virtuosas y abyectas que han cobrado estados y principados, detallando la dosificación correspondiente a violencias y favores que habrá de producir un príncipe para conservar su poder (Maquiavelo, 
2011: 31). Foucault señala que las ideas respecto del gobierno expuestas en el célebre texto producen un arco de tensión que va desde el siglo xvi al xviII y son esenciales para el devenir del problema del gobierno en la gubernamentalidad (Foucault, 2006: 115).

En el contexto de la caída de las certezas de la tradición y la religión, se advierte el surgimiento de una serie de textos, en pugna con Maquiavelo (Foucault, 2006: 114-119), concentrados en definir los fundamentos del «arte de gobernar». En la interpretación del florentino, el gobierno del príncipe se presenta como una modalidad de gobierno entre otras que son interiores a la sociedad o al estado (Foucault, 2006: 117). Lo destacable, según Foucault, es que en dichos textos se acentúa la existencia de una continuidad ascendente y una continuidad descendente, ambas vigiladas por un tipo preciso de saber. Así, por un lado, se plantea que quien quiera gobernar el Estado deberá ser capaz de gobernarse a sí mismo; luego, saber gobernar a su familia, para finalmente tener la capacidad de gobernar el Estado. Salvaguardar esta continuidad sería el objeto de las artes de gobernar; y, por otro lado, se plantea que la continuidad descendente se manifiesta como una causalidad desde el buen gobierno del Estado hasta el buen gobierno de sí mismo, pasando por el gobierno de la casa.Tal sería el problema que aborda la policía. Ambos saberes, sin embargo, poseerían un elemento central: la economía. ${ }^{2}$

En razón de este eslabón común, la continuidad ascendente y descendente del poder nos parece un asunto clave, en la medida en que remece ciertas distinciones hechas por Aristóteles en la Política y se evidencia el franqueo de un límite previsto por el estagirita, como es el límite o diferencia cualitativa establecidos entre oîkos y pólis, esencial para la definición y práctica de la ciudad y la ciudadanía (Landaeta y Espinoza, 2013: 175). Este límite es, pues, la distancia que se establece entre necesidad y libertad, ya que mientras en el ôkos la autoridad paterna vigila los asuntos relativos a las necesidades o al mero «vivir», en la polis, observando el carácter libre

2 Eco de la concepción de las artes de gobernar es la concepción de la «razón de estado» que, según Foucault, emerge a partir del encuentro de la diplomacia militar -cuyo fin es la organización de alianzas- y de la policía - cuyo fin es hacer crecer las fuerzas del estado- en una época en que se produce el desarrollo del comercio y la circulación monetaria interestatal, fuente del capitalismo. El filósofo recoge varias definiciones de la expresión «razón de estado», y a partir de ellas traza un plano de correspondencias y, aunque no tan presentes, de discrepancias. Por ejemplo, retoma la definición de Botero en Raison et gouvernement d'État en dix livres: "conocimiento perfecto de los medios a través de los cuales los estados se forman, se refuerzan, duran y crecen» (Foucault, 1994a: 150). También la de Palazzo en Discours sur le gouvernement et la veritable raison d'État: «un método o un arte nos permitirán descubrir cómo hacer reinar el orden y la paz en el seno de la República» (Foucault, 1994a: 150). 
de los ciudadanos, el asunto es la felicidad o el «vivir bien» (Pol. 1252b5 1253a13). Por ello es que se puede hablar de una inversión de los postulados de Aristóteles, en cuanto se percibe como eje de la relación de los círculos de gobierno una primacía del gobierno familiar, inversión que para algunos cabe retratar como una confusión que está a la base de toda la apropiación moderna de la idea de polis (Cavaletti, 2010). Preguntas del tipo: cómo introducir la economía en la gestión del Estado; cómo administrar a los individuos a la manera en que gestiona su hogar un buen padre de familia, son las cuestiones fundamentales que se plantea un soberano. ${ }^{3}$ En esta inversión del modelo aristotélico, gobernar un estado consistiría en poner en práctica la economía a nivel de toda la esfera estatal, es decir, tener con respecto a las riquezas y a las conductas de todos y cada uno de los individuos una forma de vigilancia no menos atenta que aquella puesta por el padre de familia sobre su casa y sus bienes. Foucault lo expresa sin vacilación: «La introducción de la economía dentro del ejercicio político será, creo, la apuesta esencial del gobierno.» (Foucault, 2006: 120).

Esta fusión de la imagen del padre y el soberano o la iteración del modelo económico familiar en la organización y gestión de los asuntos del Estado, determina, pues, en concreto, el funcionamiento del poder como una soberanía del territorio (Foucault, 2006: 28), gestionado al modo de una «gran casa». Lo esencial allí es la ley que separa y escinde el interior del gobierno del afuera inhóspito que lo acecha. Dos fuentes sostienen esta inversión del orden político aristotélico. El primero establece relación con el descubrimiento y apropiación de la polis como referente político para el mundo moderno (Cambiano, 2003). Como muestra Cavaletti, la casilla ocupada por la vida política, entendida como una ciudadanía activa que busca definir junto con otros en qué consiste el «buen vivir», es ocupada en el mundo moderno por la policía, que resuelve a priori, en connivencia con la religión, en qué consiste la felicidad de los hombres que habitan pasivamente la ciudad (Cavaletti, 2010: 122-126). El segundo se refiere a la incidencia creciente de la arquitectura en la concepción del orden y definición de las funciones de la ciudad en el marco de la proyección la «ciu-

3 El tema de la casa como modelo de la ciudad se halla con fuerza en los franceses Jean Talpin y Jean Bodin. Talpin, en una línea muy platónica, cifra la definición del orden de una comunidad en el «bien mandar» y "pronto obedecer», fundándose en la analogía del cuerpo, como lo hace también el neoplatónico Filarete, donde lo inferior se pliega a las órdenes de lo superior; así también en analogía con la casa, donde el padre gobierna los hijos. Sería interesante contraponer esta oposición entre continuidad ascendente/continuidad descendente con el discurso de la teoría ascendente del poder que se estructura desde las luchas entre el papado y los conciliaristas (Ullmann, 1999). 
dad modelo» (Landaeta y Espinoza, 2013). En tratados como el de Alberti, el célebre De re aedificatoria, se advierte, en primer lugar, que el arquitecto se presenta como el maestro de la ciudad, arrebatando su lugar al filósofo y al político, ya que en su saber se deposita el verdadero arkhé de la ciudad que conjuga utilidad, seguridad y placer (Alberti, 2004: 15); y, en segundo lugar, se advierte que casa y ciudad difieren solo en escala o, en otras palabras, que la ciudad es solo una casa de mayor dimensión (Vercelloni, 1996: 38-39). ${ }^{4}$

Para el gobierno soberano, «economía» designa una forma de gobierno estrictamente relacionado con esta policía del territorio. Más tarde, en el siglo xviII, en cambio, el término pasa a designar un campo de intervención. Para ello es necesario que acontezca una nueva mutación, un nuevo desplazamiento. Nos referimos a la emergencia de un nuevo campo de relaciones sobre el que se ejerce el gobierno del estado y en el que concursan una serie de saberes, donde el padre y la familia son despojados de su investidura de modelos para convertirse en instrumento de estos saberes. Lo que define este nuevo campo -o nuevo dispositivo- es el vínculo de economía política y policía para la sistematización de una ciencia de gobierno positiva. Esta ciencia de gobierno toma distancia del problema y de la retórica de la soberanía y corta todo nexo con la "polemología», con la teorización del conflicto como condición de la vida. Igualmente renuncia a fundamentar el poder soberano mediante una apelación al estado derecho $-\mathrm{y}$ al monopolio de la violencia- como superación al estado de naturaleza.

Foucault es enfático en afirmar que mientras las instituciones del Estado sean esencialmente instituciones de soberanía, que mientras la idea de gobierno se vea absorbida por un modelo concreto como el del gobierno de la familia, la ciencia del estado aún no verá el día. Por ello es clave indagar en este cambio, que es movido no tanto por condiciones internas a la discusión política, sino por el azote de catástrofes derivadas del crecimiento de habitantes de las áreas metropolitanas en Europa, como es el de la viruela, que deriva en el surgimiento de la noción de la población en estadística (Foucault, 2006: 26). A raíz de la importancia que adquiere este sujeto difuso que es la

4 Para ejemplificar esto es interesante apuntar a la comprensión de la ciudad en la evangelización en América Latina que se inicia tras la Conquista, entendida como una "puesta en policía de los territorios» (Gutiérrez, 2008: 58), donde se puede notar cómo confluyen ambos elementos en la iteración del modelo urbano del damero (Landaeta y Espinoza, 2015). A diferencia de Europa, con sus cambios progresivos, la ciudad en la Conquista se implanta en poco tiempo midiendo, organizando el territorio. Funciona como un dispositivo que busca, primero, engendrar el orden en el alma de los sujetos, imponiendo un modelo de costumbres y creencias que pone coto a la amenaza del afuera indígena, y, segundo, potenciar la circulación de ideas y mercancías entre el nuevo mundo y la sede del Imperio (Landaeta y Espinoza, 2013). 
población, se inicia la búsqueda de un estatuto económico específico, precisamente en el abandono del modelo del ôkkos, para transformar la concepción del estado y sus instituciones en un problema que atañe exclusivamente a la constitución de un campo de saber. El problema de la población, visto desde el prisma de la estadística, muestra que el modelo de la familia ya no surte efecto alguno y, por tanto, advierte que es esencial centrar la economía del estado en algo distinto. Igualmente, mostrará que la población posee sus normas propias y que sus acontecimientos son irreductibles a los protagonizados por el conjunto familiar. Con ello, la familia, perdiendo su carácter de modelo, pasa a convertirse en instrumento privilegiado para el gobierno de las poblaciones (Foucault, 2006: 132), desde la perspectiva económica: «la constitución de un saber de gobierno es por completo indisociable de la constitución de un saber de todos los procesos que giran alrededor de la población en sentido lato, lo que se llama justamente "economía" (Foucault, 2006: 133).

Lo preponderante, el objeto de gobierno y economía, según Foucault, no es el territorio, por lo mismo no es tanto el orden de la ciudad, ni la justa repartición de su espacio, cuanto lo urbano, aquello que por definición carece de límite orgánico. Y el gran responsable de ese asentamiento de límite difuso es la policía, cuyas principales tareas son salvaguardar la higiene, circulación de individuos y mercancía, tanto como vigilar la seguridad de esa población fluctuante. Por este hecho, las transformaciones en la esfera del gobierno y la economía no pueden comprenderse sin conocer las variaciones que experimenta la propia idea de policía y su influencia en el saber social.

\section{POLICÍA Y SABER SOCIAL}

Los usos y derivaciones que experimenta el término policía en la modernidad, junto con las ideas y prácticas que involucra, encuentran un lugar de privilegio en el marco del citado seminario de Foucault Seguridad, Territorio y Población (1977-1978). Algunas de las representaciones de la policía, no del todo desligadas, que allí están desarrolladas se analizarán en lo sucesivo. La policía en un principio, muestra Foucault, se presenta como un conjunto de reglas que velan por el orden de la ciudad, orden que conjuga el mantenimiento de la belleza del espacio habitado y el resguardo de la conducta moral de sus habitantes; posteriormente, en un salto de escala, se advierte que "policía» no se predica del orden de la ciudad, sino de la 
completa organización del territorio a la manera de un organismo, cuyos órganos son las ciudades, todas ellas bien conectadas con su capital, cuya circulación en definitiva favorece el buen desarrollo del comercio. Lo fundamental en este punto es destacar cómo la soberanía interviene el territorio, no bajo la forma de un mero reglamento externo, que asegura el mantenimiento de un orden ya existente, sino bajo la forma de una intervención de tipo económica que, junto a la regulación de las distintas acciones de sus ciudadanos, penetra en el mecanismo de lo social bajo la premisa de que interviniendo lo social y propiciando la felicidad de los individuos habrán de incrementarse las fuerzas del estado. Posteriormente, se ve que la policía conoce una nueva transformación, movida por el surgimiento del problema de la población para la estadística, donde toma también parte (Foucault, 2006: 361). El ámbito de la policía no es ahora el de la ciudad o el del territorio que se organiza a partir de la imagen de la ciudad, sino el de la metrópolis. Para Foucault, este es el momento en que la policía pierde su lugar de privilegio, pues el gobierno de la población termina siendo asumido por una nueva perspectiva económica que abjura de su intervencionismo. En este caso, según creemos ver, acontece algo distinto: si existe una notoria retirada de la policía, si su protagonismo en la cuestión urbana decae, es porque resulta integrada por el naciente «saber social». Por tanto, no es que la policía quede reducida a su carácter represivo, antes bien solo conoce un nuevo cambio al ser asumida por el «saber social», cuestión esencial para salvar la distancia que se establece entre la ciudad, el territorio y la metrópolis. Detengámonos brevemente en dichos momentos.

Policía, a comienzos de la modernidad, posee distintos sentidos: es, primero, sinónimo de una comunidad regida por una «autoridad pública»; segundo, permite referirse a la manera de gobernar dicha comunidad y, tercero, aparece como sinónimo de «buen gobierno». Todos ellos se conservan intactos entre los siglos XV, XVI y comienzos del XVII (Foucault, 2006:357). No obstante, más tarde, $y$ hasta mediados del siglo xvIII, se introduce en la idea de policía una perspectiva económica: policía se asocia a la necesidad de incrementar las fuerzas del estado, asegurando su "esplendor», esplendor que se expresa en la ciudad y sus ciudadanos (Foucault, 2006:358). ¿A qué actividades concretas se consagra la policía? Al número de ciudadanos, pues es necesario que nazcan y crezcan individuos que puedan defender y hacer fuerte un estado; necesidades de la vida: no solo debe resguardar su número, sino vigilar que cuenten con los medios alimentarios y de habitación para su subsistencia; salud: es necesario que los hombres se multipliquen y tengan asegurado su alimento, junto con ello, que puedan vivir en ambientes sanos; 
comienza por entonces la preocupación por la higiene en las ciudades, por la limpieza y amplitud de sus calles, etc.; asegura la circulación en varios aspectos: la circulación de mercancías y objetos que producen los hombres, junto con la vigilancia de las rutas de circulación, caminos, canales, etc.; finalmente, asegurar la circulación de la ley, de reglamentos a lo largo y ancho del territorio. En suma, lo esencial para la policía en esta época es garantizar la coexistencia de los hombres, de la gran familia que forman, en un territorio, no solo de acuerdo al vivir, sino al incremento de su «bienestar» para el beneficio del propio estado. Bienestar es precisamente el término que marca el paso de la preocupación por el mero vivir al vivir bien, porque en la policía precisamente se conjuga la felicidad de los individuos con la fortaleza del estado (Foucault, 2006: 375-378).

Lo que cabe destacar es este cambio de escala que incide también en la aparición de un nuevo aspecto cualitativo: en principio, la policía es comprendida como la reglamentación externa que vincula de acuerdo a un orden moral ciudad y ciudadanos, luego viene a nombrar aquello que, tomando por modelo la ciudad, reglamenta el territorio del estado a partir de una mirada económica, asegurando la coexistencia, el vivir y el bienestar de los hombres, como un padre que cuida de sus hijos. En ese momento, la policía no es ya un mero reglamento externo, sino una ciencia que busca introducirse en los mecanismos de la sociedad (Foucault, 2006: 272).

La instauración de la policía, el paso de la idea a creación a un poder que no es ni militar ni del todo político, depende estrechamente de las condiciones que sienta el capitalismo. Según Foucault, el capitalismo exigió la sistematización de la vigilancia de los hombres para su integración en el trabajo. En esa línea, destaca que, a diferencia de otros países, en Francia se produce tempranamente la estatización de los mecanismos disciplinarios para formar parte de la «policía», órgano encargado de «todo lo que sucede» o de «las cosas de cada instante» (Foucault, 1975: 214-215). En cuanto dispositivo disciplinario, ${ }^{5}$ policía se comprende como un ensamble de elementos heterogéneos: discursos, instituciones, arquitectura, reglamentos, etc., respondiendo sistemáticamente a los asuntos que afectan a las grandes ciudades y a sus estados correspondientes. Este dispositivo constituye un mecanismo que instituye dominios, técnicas y objetivos, que concibe y proyecta su intervención en distintos ámbitos de la sociedad,

5 El surgimiento del concepto de dispositivo viene a poner en relación las prácticas discursivas con lo no discursivo. En palabras de Foucault, dispositivo: «ensamble resueltamente heterogéneo que comporta discursos, elementos arquitecturales, decisiones reglamentarias, leyes, medidas administrativas, enunciados científicos, proposiciones filosóficas, morales, filantrópicas, en suma: lo dicho, como también lo no-dicho, tales son los elementos del dispositivo» (Foucault, 1994b: 299). 
siendo el encargado de tejer una compleja red donde se aseguran, por ejemplo, el control de la correcta disposición de los precios en el mercado, el cuidado y hermoseamiento de la ciudad, la rehabilitación e higiene de lugares «enfermos», el cuidado y asistencia de los pobres, la educación, la cultura, etc.

Algo es importante de notar: la disparidad de objetos que asume en tanto dispositivo es la contraparte del descrédito de la política, como lo señala Von Justi: la política, a diferencia de la policía, se reduce a su labor de guardiana del estado, en estado de guerra latente contra enemigos internos y externos. En cambio, la policía, esta ciencia de las cosas «menudas» de la vida, encierra un sentido contrario a todo belicismo, ya que se consagra al doble objetivo de velar por la felicidad de los individuos y el vigor del Estado (Justi, 1784: xII). Al momento de investirse no solo como la única ciencia, sino como el único órgano eficazmente orientado a la conquista de la felicidad de los ciudadanos, la policía se concentrará en satisfacer todo aquello que compete a la reglamentación de la sociedad con el fin de que esta llegue funcionar «automáticamente».

No obstante, tal carácter exhaustivo de la policía, tal presencia efectiva en el control de la sociedad desde una economía que no pierda de vista la imagen de un buen padre, manifiesta un giro radical solo con el surgimiento del liberalismo: la cuestión no es ahora cómo gobernar una sociedad como un padre su familia, sino cómo gobernar lo menos posible obteniendo los mejores resultados o a partir de la menor intervención. He ahí que acontece la unión de policía y ciencia social que necesita ser profundizada. Pues la desaparición del poder visible de la policía sobre el estado organizado como un territorio a partir de la ciudad, abre el campo de acción del saber social sobre aquello que rompe con el límite orgánico de la ciudad: la metrópolis. Este conocimiento se presenta como un proyecto fisiocrático de ciencia económica, que no traduce solamente el arribo de un nuevo espíritu científico, el positivismo, sino de un nuevo hacer político concebido como práctica administrativa (Damamme, 1995: 7).

Lo social - en tanto cuerpo político objetivado- deviene el eje sobre el que se ejerce un saber proyectivo que busca, según principios científicos, salvaguardar la vida del hombre en las escalas individual y colectiva. Las "ciencias del hombre» reciben así su apelativo de la unión de las perspectivas correspondientes al mundo natural y espiritual, sentando, claro está, la subordinación del segundo al primero. De acuerdo con esto, el conjunto de los seres humanos se presenta como un objeto físico, calculable, manejable, tal y como sucede con los organismos vivos que pueblan la superfi- 
cie terrestre. Esto permite que la humanidad sea introducida en un nuevo mapa, un mapa de lo social, trazado por el mismo compás de la cartografía aplicada que dividió el territorio del globo terrestre entre pueblos conquistables y recursos disponibles.

En tal escenario, el principal afectado será el pensamiento político que, pese a conservar su nombre, pierde todo valor especulativo para convertirse en mera aplicación del derecho. En ese tenor pueden inscribirse las ideas de Auguste Comte, sintetizados en un brevísimo pasaje de su correspondencia. En una carta fechada el 8 de septiembre de 1824, Comte escribía a M. Valat: «existen leyes determinadas tanto para el desarrollo de la especie humana como para la caída de una piedra» (Dhombres y Dhombres, 1989:534). Comte buscaba el reconocimiento general del nuevo aliento científico que se arrogaba la potestad de haber descubierto en lo social un objeto plausible y, lo que es lo mismo, apropiable. En suma, lo relevante, siguiendo el análisis de Damamme, es la investidura científica y, más aún, experimental de las aproximaciones al campo político, más que los objetos y los enunciados mismos, que parecen idénticos a los de la filosofía política.

Con el nacimiento de esta nueva perspectiva científica de lo social, saberes canónicos como la filosofía de la historia, el pensamiento político y moral verán su campo allanado, acelerándose un desplazamiento inédito en el modo de comprender la política, que abandona lentamente una larga tradición especulativa para reconocerse eminentemente positiva y técnica. La ciencia, en su interés por el becho bumano contemporáneo, por su existencia colectiva, se vuelca por completo sobre la realidad prosaica, tomando indistintamente por objetos sociedad, economía, derecho natural y medio urbano. Esto último retiene en buena medida la tensión y rivalidad que se experimenta entre «política especulativa»y «ciencia positiva», cuyo campo de análisis, la sociedad, se pretende fuera de todo margen de opacidad en virtud del encuentro entre ciencia y mercado.

En este contexto se produce una devaluación positiva de la política - definida por la idea de un conflicto, de un antagonismo «salvaje» entre los hombres a nivel de los pasiones-, para emerger en su lugar una perspectiva económica de la mecánica del mundo y de la sociedad (Damamme, 1995: 20); de la organización de lo social como un mercado o concurrencia de competidores que supone la necesaria intervención de la policía para (res) guardar el orden o más bien para asegurar el dinamismo en su gestión. En otras palabras, la devaluación de la política solo se consuma en el encuentro de la ciencia positiva con el liberalismo en su concepción del indivi- 
duo. Solo entonces se produce la configuración de un nuevo saber-poder político, concentrado, específicamente, en el análisis de la producción de riquezas que vendrá a encontrarse con el estudio de las facultades del hombre. En los términos en que lo presenta Simmel, la naturaleza del hombre es la de un animal que intercambia y no meramente la de un animal político (Simmel, 1987: 355). Por todo ello, se presenta un problema sin parangón en la historia del pensamiento político, un problema que afecta desde entonces a la concepción de la sociedad y del medio que esta ocupa.

El nacimiento de la ciencia social y su interés por reinar sobre la sociedad anula en el plano político la vigencia histórica de la idea de soberanía (cf. Damamme, 1995:20), puesto que para la administración del cuerpo social bastaría con el conocimiento de los principios que rigen el cuerpo político. Sin embargo, no puede pasarse por alto lo siguiente: los nuevos principios para la administración de lo social no se separan sino que se fundan en la idea aristotélica de que los hombres son naturalmente sociales ( $c f$. Aristóteles, 1988: 1253a, 50-51), confiando en que el mercado se ofrece como cura de las necesidades colectivas. El escenario que vemos conformarse y coronarse como el más alto peldaño de la ciencia es, con lo cual, el del renacimiento de los principios más antiguos de la política... pero sin metafísica. En otras palabras, la ciencia moderna actualizaría y otorgaría estatuto científico a las intuiciones de esos primeros pasos de la política trazados por Aristóteles en la Política, esta vez para el estudio del hombre considerado como organismo vivo y como miembro de lo social. En suma, lo que es puesto fuera de este cuadro es, por un lado, la idea de que el hombre se ve forzado a erigir un soberano para su propia seguridad $y$, por otro lado, que los hombres forman un conjunto disperso individuos que se reúnen por voluntad de un príncipe, ideas que sostienen el supuesto de un origen «salvaje» de la política.

La política, contra la retórica y la mitología de la soberanía y su estado original de violencia, se ofrece desde entonces como un orden ya organizado al que el hombre adviene sin mediar voluntad alguna. Lo fundamental es comenzar por el hecho social del hombre: a este se le conoce en su vida en la ciudad, que no es cualquier comunidad, sino el único lugar posible en que puede desarrollarse $-\mathrm{y}$ mejor- su vida social: la ciudad y, como hecho moderno, la metrópolis. Así, el conflicto y el antagonismo social son en este caso derivados de una cuestión más esencial, que es el medio inmanente a la sociedad: la ciudad. Y es en ese medio donde conflicto y antagonismo pueden ser educados. En la ciudad pueden rectificarse tanto el 
amor al poder como los deseos de los individuos que, buscando su propio placer, se desprenden de la unidad que deben formar en tanto que ciudadanos. En suma, lo urbano es ahora, gracias a las instituciones nacidas de las manos del saber social, un apéndice de la naturaleza que le asistirá en la tarea de llevar a su destino a seres naturalmente sociables: crecer en un perfecto «aislamiento colectivo». La nueva realidad urbana deberá ser capaz de erigirse como el instrumento que potencia la salud de la población y, por ese camino, de la nación. La tarea será entonces atender a las bases biológicas de lo social con el fin de diagnosticar aquello que lo debilita y conocer con ello mismo aquello que lo fortalece. Ahí es cuando la política se reconoce como un affaire eminentemente técnico, borrando el límite que la separa de la policía, al momento de combinar la administración con el cultivo de un saber proyectivo.

\section{LA CUESTIÓN URBANA: DISLOCACIÓN DE LO POLÍTICO Y VIGENCIA DE LA POLICÍA}

Lo dicho en el apartado anterior acerca de la erosión de lo político con la emergencia de un saber positivo de lo social que subsume los principios de la policía, contextualiza la lectura o diagrama de la cuestión urbana en el trabajo de Foucault. En diversos pasajes, el filósofo pone en evidencia la diferencia existente entre el interior disciplinario de la ciudad y el horizonte abierto del biopoder, que se ejerce como un gobierno de las poblaciones «metropolitanas», sin analizar esta diferencia en términos de progreso y superación, o incluso aceptando una cierta superposición de dichos horizontes (Salinas, 2014: 80). Así, pues, mientras que la disciplina, en tanto técnica, actúa localmente sobre individuos aislados distribuyéndoles en un espacio en el que se producen discursos y prácticas de sujeción (Foucault, 1975: 200), el gobierno de las poblaciones en el biopoder, en tanto tecnología amparada en un conjunto de saberes, opera sobre el conjunto de la sociedad para concretar su propia «libertad». Por ello, es el conjunto de la sociedad y no la parte, el individuo aislado, el «ámbito» sobre el cual comienzan a interrogarse las ciencias sociales, interiorizándose en los elementos y partes de la nueva polis que se amplía hasta una dimensión inédita y cuyo mismo crecimiento someterá la experiencia de la ciudad a una transformación cualitativa sin comparación.

Aquello que permite comprender la crisis del interior disciplinario es la especial incidencia del discurso económico liberal en la articulación de la 
relación Estado-sociedad. La transformación que provoca en la sociedad el mercado capitalista no se reduce tan solo al plano de los intercambios económicos, sino que afecta al conjunto de las relaciones entre individuos, así como a los vínculos de estos con el Estado. Si ello es así, es porque el Estado no solo ampara unos saberes que yacen por completo permeados por su influjo, sino que auspicia su proliferación para generalizar la forma de intercambio como medida de las relaciones humanas, en su aparente retirada o característico laissez faire. Es clave, en el marco de los estudios de Foucault en torno a la biopolítica, comprender que el propio estado no es sino otra pieza en el escenario que teje el biopoder en la aparición del liberalismo (Salinas, 2014). Lo mismo puede decirse de la ciudad y el espacio urbano, que dependen -incluso hasta nuestros días- de la puesta en juego del ideal de vida desocializada - e inmunizada- que propala el dispositivo securitario del liberalismo. Atender, por ello, brevemente a las transformaciones que se operan en la concepción y uso del espacio en el decurso de la modernidad nos permitirá enmarcar la importancia creciente de la noción de "circulación».

Para el gobierno, desde el punto de vista de la soberanía, la cuestión esencial es capitalizar un territorio, vale decir, jerarquizar y distribuir la ciudad a la manera de un organismo. Para la disciplina, en cambio, el asunto es la constitución artificial, la arquitecturación de espacios cerrados que permitan producir unas determinadas conductas. La seguridad, con relación a ambas, produce un nuevo desplazamiento: para esta lo fundamental es el acondicionamiento de un medio en una situación espacial dada para el fomento de la circulación: circulación de individuos, de tropas, de enfermedades, entre otros acontecimientos probables, beneficiosos o nefastos, con que toda ciudad debe enfrentarse. Por todo esto, se puede decir que el trabajo del arquitecto en cada caso es distinto. En la soberanía, el arquitecto cumple con el deseo regio de crear ciudades justas, atendiendo, por un lado, a su disposición jerárquica en el territorio y, por otro lado, a las diferentes cualidades de sus habitantes en cada caso; en la disciplina, la labor del arquitecto es comparable a la del gran artesano que insufla en las criaturas el impulso vital que les permite orientarse hacia el bien, siguiendo el orden de un espacio distribuido de acuerdo a una jerarquía que no pierde de vista el lugar esencial del mercado. En el dispositivo de seguridad asistimos a una mutación importante: el problema no es ya el diseño de una ciudad o la constitución o arquitecturación de un espacio, en esa medida, el acondicionamiento que lleva a cabo excede la labor del arquitecto. La gestión de la circulación, movida por la emergencia del problema del 
medio, es de hecho urbano más que arquitectónico, pues concursan una serie de disciplinas (Foucault, 2006: 41).

El medio es el soporte de la circulación, y aunque no esté presente en el vocabulario de los arquitectos, ni en el de los urbanistas, es siempre aquello que está presente en el modo en que los urbanistas intentan reflejar y modificar el espacio urbano: «los dispositivos de seguridad trabajan, fabrican y organizan y acondicionan un medio aun antes de que la noción se haya constituido y aislado» (Foucault, 2006: 41). Es el medio, en definitiva, el lugar de la política o, más bien, de la policía, que vela por la circulación de la mercancía. Solo así se comprende que la ciudad deje de ser la idea y el lugar de la política para convertirse en "función» de la policía.Y si este hecho tiene por principal efecto que en la metrópolis el ciudadano se reduzca a mero consumidor es porque, como explica Foucault, el propio mercado y el comercio devienen modelo para la realización de toda entidad urbana (Foucault, 2006: 383).

Tomando ligeramente distancia de Foucault, se observa que el funcionamiento del medio, previo incluso a la elaboración del concepto, nos remite a su raigambre policial y muestra el urbanismo, tan interesado en su delimitación, solo viene a trasplantar los principios de la policía en un campo autónomo que en el siglo veinte subsumirá, según Le Corbusier, los esfuerzos de la propia arquitectura (Le Corbusier, 1963: 11-12). En esa línea, para un análisis comparado del trabajo de Foucault, vemos que, frente al porvenir cabe distinguir dos fenómenos distintos pero íntimamente ligados: por un lado, cabe considerar lo urbano como el objeto de un saber que da lugar a un conjunto de prácticas para la gestión, matematización y codificación de la circulación con fines estrictamente económicos; y, por otro, lo urbano, como pura función, independiente del saber que lo toma por objeto, puede considerarse en tanto «abstracción concreta» (Lefebvre, 1968: 78; Toscano y Kinkle, 2015: 227) que opera la homogeneización creciente y constante de todo territorio, y de toda relación social. Ambos fenómenos, se puede decir, definen el marco en que, más allá de la metrópolis, se modela la cuestión urbana en nuestros días donde lo local se subordina a lo global, modelando la geografía del capital (Harvey, 2008: 84), forzándonos a comprender las nuevas formas de racionalidad que sostienen la fragmentación urbana y, asimismo, las acciones concretas de grupos e individuos por reapropiarse de la ciudad y su territorio. 


\section{CONCLUSIÓN}

Para llevar a cabo el diagrama de la cuestión urbana en Foucault, hemos presentado las primeras fases de la construcción de la idea de gobierno y en qué circunstancias se produce su relación con la policía. Esencial en esta primera etapa fue destacar la importancia del modelo de la familia para la formulación de una comprensión del gobierno en que el soberano administra el estado, su territorio, a partir de la unidad básica que es la ciudad, a la manera en que un padre gestiona el hogar, es decir, introduciendo la economía en el ejercicio político a fin de hacer crecer las fuerzas del estado. Luego, advertimos que, sin abandonar la esfera económica, pero buscando dar con su estatuto de saber específico, con el surgimiento del problema de población, lo urbano se descubre como el asiento del gobierno. Este primer abordaje nos hizo analizar no un punto sucesivo, sino un contrapunto, observando una historia que corre paralela al problema del gobierno: la relación de policía y saber social. Profundizamos brevemente en la concepción de la policía hasta recibir su investidura científica, con el fin de mostrar su importancia ascendente hasta integrarse en el «saber social», síntesis de la neutralización de las ideas políticas y diatribas que giraban en torno a la soberanía y al arte de gobernar. Se advirtió que el saber social se autoproclamaba el saber de las cosas humanas y aseveraba, atendiendo a las bases biológicas de la conducta y utilizando el medio urbano como instrumento, poder dar respuesta a toda demanda colectiva. Finalmente, nos enfocamos en el estudio de la cuestión urbana como el cruce de los puntos uno y dos, a fin de intentar comprender cómo opera y en qué modo desafía al pensamiento filosófico. Estableciendo las diferencias entre la concepción del espacio para el interior disciplinario de la ciudad y la apertura de la seguridad metropolitana, abordamos el problema de la relación del medio y la circulación, donde nuevamente la policía manifestó su relevancia: la circulación no solo se revela como el problema esencial de la cuestión urbana, sino que además se revela como el principal acelerador de la reducción del ciudadano al consumidor -tema que se anuncia como un elemento fundamental para el urbanismo en el siglo xx, por ejemplo, bajo la égida de Le Corbusier. Lo urbano, finalmente, se nos presentó -incluso con independencia del saber que supuestamente lo controla-, en tanto que pura función, como la abstracción concreta que generaliza la forma intercambio como medida del territorio y de toda relación social, hecho que está en la base del marco de la cuestión urbana actual. 


\section{REFERENCIAS BIBLIOGRÁFICAS}

ACANDA, J. L. (2001): «Poder y revolución. Claves para asimilar a Foucault», Recerca, Revista de pensament $i$ anàlisi, 1, pp. 69-93.

Alberti, J. B. (2004): L'art d'édifier, París, Seuil.

Aristóteles (1988): Política, Madrid, Gredos.

Cambiano, G. (2003): Polis. Histoire d'un modèle politique, París, Aubier.

Castells, M. (1977): The urban question. A marxist approach, Londres, Edward Arnold.

Cavaletti, A. (2010): Mitología de la ciudad. La ciudad Biopolítica, Buenos Aires, AH.

Deleuze, G. y Guattari, F. (1993): ¿Qué es la filosofía?, Barcelona, Anagrama.

Damaмme, D. (1995): «Entre science et politique. La première science sociale», Politix, Vol. 8, núm. 2, pp. 5-30.

Dhombres, N. y Dhombres, J. (1989): Naissance d'un nouveau Pouvoir: sciences et savants en France 1793-1824, París, Payot.

DuQue, F. (2003): Los buenos europeos. Hacia una filosofía de la Europa contemporánea, Madrid, Nobel.

Foucault, M. (1975): Surveiller et punir. La naissance de la prison, París, Gallimard.

- (1994a): «Omnes et singulatim: vers une critique de la politique», en Foucault, M. (1994): Dits et écrits IV, 1980-1988, París, Gallimard, pp.134161.

- (1994b): «Le jeu de Michel Foucault (entretien sur l'histoire de la sexualité)», en Foucault, M. (1994): Dits et écrits III, 1976-1979, París, Gallimard, pp. 298-327.

- (2004): Naissance de la biopolitique, Cours au collège de France (1978-1979), Hautes Études, París, Gallimard-Seuil.

- (2006): Seguridad, Territorio, Población. Curso en el Collège de France (1977-1978), Buenos Aires, FCE.

Gutiérrez, R. (2008): «Otros urbanismos hispanoamericanos» en VV AA (2008): Urbanismo y vida urbana en Iberoamérica colonial, Bogotá: Alcaldía Mayor de Bogotá, pp. 51-70.

Harvey, D. (2008): Géographie de la domination, París, Les Prairies ordinaires.

LANDAETA, P. y Espinoza, R. (2013): «El fin histórico de la ciudad. Acerca del vínculo entre arquitectura y policía», Ideas y valores, vol. LXII, núm. 151, pp. 169-194. 
LANDAETA, P. y EsPinOzA, R. (2015): «Cartografía de la ciudad latinoamericana.

Fundación del orden colonial», Ideas y valores, vol. LXIv, núm. 157, pp. 7-36.

Le CORBusIer (1963): Manière de penser l'urbanisme, París, Gonthier.

Lefebvre, H. (1968): La vie quotidienne dans le monde moderne, París, Gallimard.

Maquiavelo, N. (2011): «El príncipe», en Maquiavelo, N. (2011): El Príncipe y otras obras, Madrid, Gredos.

SALINAS, A. (2014): La semántica biopolítica. Foucault y sus recepciones, Viña del Mar, Cenaltes.

Simmel, G. (1987): La philosophie de l'argent, París, PUF.

Toscano, A. y KinkLe, J. (2015): Cartographies of the absolute, Londres, ZeroBooks.

Ullmann, W. (1999): Historia del pensamiento político en la Edad Media, Barcelona, Ariel.

Vercelloni, V. (1996): La cité idéale en occidente, París, Félin, 1996.

Von Justi, J. H. G. (1784): Elementos generales de policía, Barcelona, Eulalia Piferrer. 